\title{
Investigation of over the Counter Diagnosis and Drug Dispensation in Chemists: A Case Study in Thika Sub-County, Kenya
}

\author{
Ndung'u Isaac Kamau \\ Department of Statistics and Computer Sciences, Moi University, Eldoret, Kenya
}

\section{Email address:}

spaceage4g@gmail.com

\section{To cite this article:}

Ndung'u Isaac Kamau. Investigation of over the Counter Diagnosis and Drug Dispensation in Chemists: A Case Study in Thika Sub-County, Kenya. American Journal of Theoretical and Applied Statistics. Vol. 4, No. 6, 2015, pp. 464-470. doi: 10.11648/j.ajtas.20150406.16

\begin{abstract}
Over-the-counter (OTC) drugs are medicines that may be obtained directly by a consumer without a prescription from a healthcare professional, as compared to drugs sold to consumers possessing a valid prescription. In many countries, Kenya included, these drugs are often located on the shelves of stores like any other packaged product. Some drugs may be legally classified as OTC but may only be dispensed by a pharmacist after an assessment of the patient's needs and/or the provision of patient education. OTC drugs are capable of being misused, abused especially where inappropriate drugs and incorrect dosages are given which may lead to short and long-term negative effects. The major concern surrounds the correct diagnosis and the appropriateness of the dispensed drugs and information provided to the consumers. This study focused on the OTC drugs in chemists. It was important to know why people opt for OTC drugs instead of the prescribed drugs. To meet this objective, an observational study was carried out in Thika Sub-county of Kenya to determine why patients prefer the OTC drugs to prescribed drugs. The results showed that the cost of prescription, source of diagnosis information, source of prescription information, amount of income of the respondent and previous experience on the same similar symptoms were determinants of buying OTC drugs. Education levels, age, place of residence, occupation and hospital type near the respondent were the covariates. The results of this study have enabled the researcher to come up with recommendations to the Ministries of Medical Services and that of Public Health on the best policies to use in dispensing OTC drugs.
\end{abstract}

Keywords: Population, Over-the-Counter Drugs, Diagnosis Information, Thika Sub-county

\section{Introduction}

The chemists in Thika are frequented by drug buyers. Majority of the buyers buy the medicine without a medical doctors' prescription. The aim of this study was to seek to establish why they buy the drugs without the doctors' prescription. A qualified drug seller in a chemist is a person trained to dispense medicine following a medical doctors' prescription and is not trained in diagnosis of an illness. The fact is that the chemist attendants sell the drugs without a prescription and at times they offer consultation regarding some illnesses. However, concerns surround the appropriateness of drugs and information that medicine sellers provide. Often the type or dose of medicine was inappropriate for the complainant (Abiola et al; 1983). In a baseline survey in Kenya, only $4 \%$ of children given storebought chloroquine received an appropriate dose and only
$2 \%$ received this recommended three-day period. (Marsh et al; 1999). Aspirin was widely used although it is not recommended for children, with $22 \%$ receiving potentially toxic doses. (Geissler et al; 2000), moreover, drugs may be as substandard quality because of poor manufacture and storage (Van der Geest; 1987). In some encounters with their customers, medicine sellers simply sell what the customer requests. Few sellers are presented with a prescription from a trained health professional, nor do they request one prior to making a sale, (Adome; 2004). In Kenya, many customers who ask for such advice from drug shop staff are often given instant diagnoses and drug recommendations, operating as storefront clinics (Ongore \& Nyabola; 1996). However, medicine sellers rarely ask customers questions about the illness and vary widely in the amount, accuracy, and quality of information given on how to take the medicines. (Nshakira et al; 2002). Instructions are often unclear, and misinformation is often provided. (Wolf-Gould et al; 1991). 
Like any business, medicine sellers maintain their existence in response to consumer demand, in this case for accessible convenient, reliable, and affordable drug supplies.

The main concern of this study was the drug dispensation to the patients without diagnosis by a medical professional, yet: The symptoms of some diseases like malaria are headache, fever, joint pains, vomiting among others. The same symptoms are also similar to that of typhoid and meningitis. The drug sellers are not able to tell accurately the disease that a customer is suffering from and at times they give the wrong drug. Indeed, the customers self-diagnosis based on their past experiences or that of the others. That is the case of customers inquiring from their friends the drugs that they are supposed to take and they just buy the drugs as per their friends' advice. Also, the danger of over the counter drug consultation is that the drug sellers do not base their prescription on any medical Doctors' diagnosis as well as frequent self-misdiagnosis.

It has repeatedly been shown that a large proportion of the public does not consider advice or information-giving to be a primary function of the pharmacist, at least not when given spontaneously (Salter et al; 2007). The reason for patients not being positive about such a role for the pharmacists could be a lack of faith in pharmacists' competence in this field (Anderson et al; 2004), fear of asking stupid questions (Schommer; 1997), having the impression that they already have all information necessary, perceiving that pharmacists have limited access to patients records (Kettis Lindblad et al; 2006) and lastly they can't ask for an over the counter prescription due to privacy issues.

The purposes of this study was to determining factors that make people prefer the OTC drugs to the prescribed drugs. The study was guided by the following specific objectives;

i. To determine the effect of cost on the preference of OTC drugs to the prescribed medicine in Thika Subcounty.

ii. To determine whether the time a patient takes to get a doctors' prescription affects the choice of drugs taken.

iii. To determine the effect of accessibility of medical health care to the preference of OTC drugs.

iv. To determine the level of customer awareness on the dangers of taking drugs without a doctor's prescription.

\section{Literature Review}

Prescription of drugs means an order to take certain medications. Prescription may also include clinical assessments, laboratory tests, and imaging studies relevant to optimizing the safety or efficacy of medical treatment. The prescription should be given by a medical professional or qualified prescriber who should take responsibility for the clinical care of the patient and in particular for monitoring efficacy and safety. Drugs need to be dispensed in formal establishments like chemists, or a health facility like a hospital. A study has shown that in some settings, the drug seller market is extremely informal, including market traders with bowls of exposed tablets and capsules among which customers pick and choose, and hawkers wandering the streets (van der Geest; 1998). This study failed to tell why the buyers of drugs buy these drugs from these informal establishments.

Studies have been done on the knowledge of drug sellers. One study done about medicine sellers has shown that medicine sellers' knowledge of drugs and doses is often poor (Massele et al; 1993). In the treatment of malaria it was established that often the type or dose of medicine is inappropriate for the complaint (Abiola, et al; 1983). Post intervention, for example, $60 \%$ of shop treated fevers still did not receive an adequate dose of a recommended anti-malaria drug in Kilifi, Kenya, (Marsh et.al; 2004). Similarly in another study about $50 \%$ of private practitioners failed to give the correct anti-malaria dose in Luwero, Uganda (Tawfik, et al; 2006). Some studies, however, have taken a different approach by looking at the relationship between selling drugs and making profit. The drug sellers in Kenya both in formal and informal facilities are concerned about money. A study has shown that limited competition was associated with high retail mark-ups in rural Kenya. (Indalo; 1997). Other studies however have shown that in most encounters with their customers, medicine sellers simply sell what the customer requests. Few sellers are not presented with a prescription from a trained health professional, nor do they request one prior to making a sale. (Fassin; 1988). It has been established in another study that chemists are not always staffed by appropriate personnel, (Goel et al; 1996). A different study has shown that instructions are often unclear, and misinformation is often provided. (Wolf-Gould et al; 1991). Many drug sellers don't offer any information regarding drugs, however; some sellers give a considerable amount of advice on drugs and doses. (Brieger et al;2004). In some cases studies have shown some dealers sell sub-optimal drug doses. (Adome, et al; 1996).

It has been shown that a large proportion of the public does not consider advice- or information-giving to be a primary function of the pharmacist, at least not when given spontaneously (Salter et al; 2007) The reason for patients not being positive about such a role for the pharmacists could be a lack of faith in pharmacists' competence in this field (Anderson et al; 2004), fear of asking stupid questions (Schommer; 1997), having the impression that they already have all information necessary and perceiving that pharmacists have limited access to patient records (Kettis et al; 2006), and some patients can't make inquiries from a chemist due to privacy issues (McAuley et al; 2009).

Although studies have shown that some medicine sellers don't have enough knowledge on the drugs they sell, (Goodman; 2004). The study does not tell why patients buy drugs without the doctor's prescription.

\section{Methodology}

\subsection{Research Design}

The study adopted a cross sectional descriptive survey. Zikmund (2003) posits that surveys provide quick and 
accurate means of accessing information on a population at a single point in time. A descriptive cross-sectional survey collects data to make inferences about a population of interest (universe) and have been described as snapshots of the populations from which researchers gather data. A survey assists the researcher to establish whether significant associations among variables exist at one point in time, depending on the resources available and the target population.

\subsection{Sampling Methods}

The study sample for patients was selected purposefully to enable the researcher interview only patients found buying drugs at chemists and drug stores without a medical doctor's prescription.

\subsection{Study Population}

Study participants were mainly recruited at community pharmacies in Thika District. They were all be adults (over 18 years old), and used medicines regularly to treat a variety of medical conditions. The recruiter used subjective judgment to exclude individuals with poor understanding of English and Kiswahili, and those suspected of suffering from cognitive impairment. Age, gender and type of drugs were monitored to get a wide variation of respondents.

\subsection{Sample Size Determination}

The sample size (n) was determined as with (Kothari; 2003) method of sample size estimate from a finite population

$$
\mathrm{n}=\frac{\mathrm{z}^{2} \text { p.q.N }}{(\mathrm{N}-1) \mathrm{e}^{2}+\mathrm{z}^{2} \mathrm{p} . \mathrm{q}}=\frac{1.96^{2} \times 0.733 \times 0.267 \times 380277}{380276 \times 0.05^{2}+1.96^{2} \times 0.267 \times 0.733}=300
$$

\section{Where}

$\mathrm{N}=$ is the total population above 19 years in the sub-county (380277).

$\mathrm{n}=$ is the sample size $=300$

$\mathrm{z}=$ value of the standard variate $=1.96$ at $95 \%$ Confident Intervals

$\mathrm{e}=$ is the acceptable error $=0.05$

$\mathrm{p}=$ proportionate target population with the particular characteristic $(p=0.733), q=1-p$

A sample size of 300 participants was estimated.

To collect the data from the 300 respondents, the population in the study area was divided into 6 stratums as per the administrative boundaries. Proportional allocation was employed to distribute the 300 respondents in to 6 stratums (6 administrative divisions).

\subsection{Data Analysis - Statistical Tests}

The study generated both quantitative and qualitative data and this data was collected and analyzed in several different ways. Data collected included structured and unstructured interviews and data from the administration of a questionnaire. Data was analyzed using the constant comparison method for qualitative research, and descriptive statistics for questionnaire data. The study hypotheses were tested using Pearson product-moment correlation coefficient to help predict relationships between independent and dependent variables. It enabled the researcher to determine the strength of the association between the two variables. The study was aimed at determining the effect of independent variables on the independent variables. The confounding factors were analyzed using logistic regression model. The study findings were discussed and presented in form of frequency tables. Interpretation of data was performed using the perspective of usefulness, which was the potential for results being applicable and useful for developing community pharmacy practice.

Table 1. Sample size Determination.

\begin{tabular}{lll}
\hline Stratum & Population & Sample \\
\hline Thika municipality & 111,174 & 49 \\
Kakuzi & 73,368 & 32 \\
Gatanga & 113,067 & 50 \\
Kamwangi (Gatundu north) & 99,291 & 44 \\
Gatundu south & 118,533 & 53 \\
Ruiru & 159,435 & 71 \\
Total & 674868 & 300 \\
\hline
\end{tabular}

\subsection{Logistic Regression Model}

If there are $p$ predictor variables $x_{1}, x_{2}, \ldots, x_{\mathrm{p}}$, the general form of multiple logistic regression model is as follows;

$$
P(D)=\frac{1}{1+\exp \left(-a-\sum_{j=1}^{p} b_{j} x_{j}\right)}
$$

Parameters $b_{1}, \ldots, b_{\mathrm{p}}$, were estimated using the maximum likelihood method. The parameter should give the significance of each independent variable to the outcome D. The estimated parameter forming the model was used to classify the remaining part of the data into either of the two groups. The outcome of the classification of the model was compared with the already known outcome. Finally, the percentage of the correctly classified data was obtained. The percentage performance was used for comparison.

\section{Empirical Results and Discussion}

\subsection{Prescription Cost and Doctors' Prescription}

Table 2. Prescription cost and Doctors' prescription.

\begin{tabular}{llll}
\hline \multirow{2}{*}{ Responses } & \multicolumn{2}{l}{ Doctor's prescription } & \multirow{2}{*}{ Total } \\
\cline { 2 - 3 } & yes & No & 206 \\
\hline Yes & 7 & 199 & 94 \\
No & 85 & 9 & 300 \\
Total & 92 & 208 & 0 \\
\hline
\end{tabular}

Chi-square Value $=229.921, \mathrm{df}=1, \mathrm{P}$-value $=0.000$

Table 2 shows the frequencies cost of prescription against a doctors' prescription. The table shows that 208 out of 300 respondents bought drugs without a prescription. 199 respondents out of 208 who bought drugs without a prescription were avoiding the cost of prescription. The ChiSquare value for the association between Doctor's 
prescription Preference and previously having the same symptoms was obtained as 229.921 with 1 degree of freedom and a Significance Probability less than 0.0001 . This implies that the association was statistically significant. On the evidence of this data there would appear to be no doubt that there is an association between a doctors' prescription Preference and the cost of prescription from which this sample of 300 respondents was drawn.

\subsection{Age Against Doctors' Prescription}

Table 3. Age against Doctors 'prescription.

\begin{tabular}{llll}
\hline \multirow{2}{*}{ Age } & \multicolumn{2}{l}{ doctor's prescription } & \multirow{2}{*}{ Total } \\
\cline { 2 - 3 } & yes & no & \\
\hline less than 21yrs & 7 & 17 & 24 \\
21-30yrs & 23 & 71 & 94 \\
31-40yrs & 25 & 55 & 80 \\
41-50years & 27 & 43 & 70 \\
above 50yrs & 10 & 22 & 32 \\
Total & 92 & 208 & 300 \\
\hline
\end{tabular}

Chi-square Value $=3.799, \mathrm{df}=4, \mathrm{P}$-value $=0.434$

Table 3 shows the distribution of age of the respondents to having a doctor's prescription. The Chi-square value is 3.799, with 4 degree of freedom and P-value of 0.434 . This implies that there exist no association between age and Doctors' prescription. This show that age is not significant in determining whether a patient will buy drugs from a chemist with or without a medical doctors' prescription.

\subsection{Information Source and Doctor's Prescription}

Table 4. Information source and doctors prescription.

\begin{tabular}{llll}
\hline \multirow{2}{*}{ Information source } & \multicolumn{2}{l}{ Doctor's prescription } & \multirow{2}{*}{ Total } \\
\cline { 2 - 3 } & yes & no & \\
\hline Doctor & 89 & 0 & 89 \\
Chemist/Pharmacy Attendant & 3 & 163 & 166 \\
Friends/Relatives & 0 & 18 & 18 \\
Own Experience & 0 & 27 & 27 \\
Total & 92 & 208 & 300 \\
\hline
\end{tabular}

Chi-square Value $=286.145, \mathrm{df}=3, \mathrm{P}$-value $=0.000$

Table 4 shows the frequencies of source of diagnosis to hospital against a doctors' prescription.

The Chi-Square value for the association between Doctor's prescription Preference and source of information (i.e who tells where the patient is suffering from) was obtained as 286.145 with 3 degrees of freedom and a Significance Probability less than 0.00001 - that is a very highly significant result. On the evidence of this data there would appear to be no doubt that there is an association between a doctors' prescription Preference and source of information from which this sample of 300 respondents was drawn.

\subsection{Residence Against Doctor's Prescription}

Table 5 shows the frequencies of residence against a doctors' prescription. The Chi-Square value for the association between Doctor's prescription Preference and residence was obtained as 0.271 with 2 degrees of freedom and a $\mathrm{P}$-value $=0.873$. This show that place of residence is not significant in determining whether a patient will buy drugs from a chemist with or without a medical doctors' prescription.

Table 5. Residence against Doctor's prescription.

\begin{tabular}{llll}
\hline \multirow{2}{*}{ Residence } & \multicolumn{2}{l}{ Doctor's prescription } & \multirow{2}{*}{ Total } \\
\cline { 2 - 3 } & yes & no & \\
\hline Urban & 26 & 63 & 89 \\
Semi Urban & 41 & 94 & 135 \\
Rural & 25 & 51 & 76 \\
Total & 92 & 208 & 300 \\
\hline
\end{tabular}

Chi-square Value $=0.271, \mathrm{df}=2, \mathrm{P}$-value $=0.873$

\subsection{Gender and Doctors' Prescription}

Table 6. Gender and Doctors 'prescription.

\begin{tabular}{llll}
\hline \multirow{2}{*}{ gender } & \multicolumn{2}{l}{ Doctor's prescription } & \multirow{2}{*}{ Total } \\
\cline { 2 - 3 } & yes & no & 143 \\
\hline Male & 34 & 109 & 157 \\
Female & 58 & 99 & 300 \\
Total & 92 & 208 & \\
\hline
\end{tabular}

Chi-square Value $=6.102, \mathrm{df}=1, \mathrm{P}$-value $=0.014$

Table 6 shows the frequencies of gender against a doctors' prescription. The table gives the Pearson chi- square test between those who had doctor's prescription and their gender. The level of significance is $0.014<0.05$. This shows that there is a relationship between the doctor's prescription and gender of the 300 respondents. More men buy drugs without a doctors' prescription than women.

\subsection{Education Level and Doctors Prescription}

Table 7. Education level and Doctors prescription.

\begin{tabular}{llll}
\hline \multirow{2}{*}{ Education Level } & \multicolumn{2}{l}{ Doctor's prescription } & \multirow{2}{*}{ Total } \\
\cline { 2 - 3 } & yes & no & \\
\hline Primary & 13 & 53 & 66 \\
Secondary & 38 & 81 & 119 \\
College & 28 & 59 & 87 \\
University & 13 & 15 & 28 \\
Total & 92 & 208 & 300 \\
\hline
\end{tabular}

Chi-square Value $=7.191, \mathrm{df}=3, \mathrm{P}$-value $=0.066$

The table 7 shows the frequencies of level of education against a doctors' prescription. The table gives the Pearson chi- square test for those who had doctor's prescription and their level of education. The level of significance are $0.066>$ 0.05. This showed that the level of education is not significant in determining whether a patient will buy drugs from a chemist with or without a medical doctors' prescription.

\subsection{Income Amount and Doctor's Prescription}

The result shows the frequencies of occupation against a 
doctors' prescription. Table gives the Pearson chi- square test for those who had doctor's prescription and the income they earn. The level of significance less than 0.005 was significant. This shows that there is a relationship between the doctor's prescription and income of the respondents.

Table 8. Income amount and Doctor's prescription.

\begin{tabular}{llll}
\hline \multirow{2}{*}{ Income Amount } & \multicolumn{2}{l}{ Doctor's prescription } & \multirow{2}{*}{ Total } \\
\cline { 2 - 3 } & Yes & No & \\
\hline Less Than 10,000ksh & 6 & 29 & 35 \\
10,000ksh-30,000ksh & 35 & 48 & 83 \\
30,001ksh-50,000ksh & 15 & 72 & 87 \\
Above 50,000ksh & 36 & 59 & 95 \\
Total & 92 & 208 & 300 \\
\hline
\end{tabular}

Chi-square Value $=17.884, \mathrm{df}=3, \mathrm{P}$-value $=0.000$

\subsection{Frequency Table for Time Taken to Reach Hospital and Doctors Prescription}

Table 9. Frequency table for Time taken to reach hospital and Doctor's prescription.

\begin{tabular}{|c|c|c|c|}
\hline \multirow{2}{*}{ Time Taken To Reach Hospital } & \multicolumn{2}{|c|}{ Doctor's prescription } & \multirow{2}{*}{ Total } \\
\hline & Yes & no & \\
\hline Less Than $30 \mathrm{~min}$ & 37 & 77 & 114 \\
\hline $30 \mathrm{~min}-60 \mathrm{~min}$ & 34 & 74 & 108 \\
\hline $61 \mathrm{~min}-120 \mathrm{~min}$ & 15 & 33 & 48 \\
\hline More Than $120 \mathrm{~min}$ & 6 & 24 & 30 \\
\hline Total & 92 & 208 & 300 \\
\hline
\end{tabular}

Chi-square Value $=1.818, \mathrm{df}=3, \mathrm{P}$-value $=0.611$

Table 9 shows the frequencies of time a patient takes to reach hospital against a doctors' prescription. The table gives the Pearson chi- square test for those who had doctor's prescription and the time they took to reach hospital. The level of significance was $0.611>0.05$. This shows that there is no relationship between the doctor's prescription and the time taken by the respondents to reach a hospital.

\subsection{Similar Symptoms and Doctor's Prescription}

Table 10. Similar symptoms and Doctor's prescription.

\begin{tabular}{llll}
\hline \multirow{2}{*}{ Similar symptoms } & \multicolumn{2}{l}{ Doctor's prescription } & \multirow{2}{*}{ Total } \\
\cline { 2 - 3 } & yes & No & \\
\hline not applicable & 77 & 126 & 203 \\
Yes & 7 & 34 & 41 \\
No & 8 & 48 & 56 \\
Total & 92 & 208 & 300 \\
\hline
\end{tabular}

Chi-square Value $=15.669, \mathrm{df}=2, \mathrm{P}$-value $=0.000$

Table 10 shows the frequencies of previous similar symptoms to hospital against a doctors' prescription. The Chi-Square value for the association between Doctor's prescription Preference and previously having the same symptoms was obtained as 15.669 with 2 degrees of freedom and a Significance Probability less than 0.005 that is a very highly significant result. On the evidence of this data there would appear to be no doubt that there is an association between a doctors' prescription Preference and previously having similar symptoms from which this sample of 300 respondents drawn.

\subsection{Logistic Regression Model Results}

Table 11. Logistic Regression Model Results.

\begin{tabular}{|c|c|c|c|c|c|c|}
\hline & B & S.E. & Wald & df & Sig. & $\operatorname{Exp}(B)$ \\
\hline$x_{1}$ & -0.117 & 0.014 & 70.469 & 1 & 0.000 & 0.890 \\
\hline$x_{2}$ & -0.036 & 0.074 & 0.2290 & 4 & 0.632 & 0.965 \\
\hline$x_{3}$ & 0.194 & 0.036 & 29.428 & 1 & 0.000 & 1.214 \\
\hline$x_{4}$ & 0.063 & 0.022 & 8.303 & 3 & 0.004 & 1.065 \\
\hline$x_{5}$ & 3.154 & 0.970 & 12.340 & 3 & 0.030 & 29.894 \\
\hline$x_{6}$ & 0.850 & 0.417 & 4.9296 & 4 & 0.286 & 3.8374 \\
\hline$x_{7}$ & 0.262 & 0.136 & 3.708 & 1 & 0.014 & 1.299 \\
\hline$x_{8}$ & 0.088 & 0.261 & 0.086 & 3 & 0.038 & 1.066 \\
\hline$x_{9}$ & -0.439 & 0.205 & 0.033 & 1 & 0.432 & 0.965 \\
\hline Constant & 2.492 & 0.180 & 191.414 & 1 & 0.000 & 12.087 \\
\hline \multicolumn{2}{|c|}{$\begin{array}{l}x_{1}=\text { Residence } \\
x_{2}=\text { Age } \\
x_{3}=\text { Gender }\end{array}$} & \multicolumn{2}{|c|}{$\begin{array}{l}x_{4}=\text { Education } \\
x_{5}=\text { Drugs_information } \\
x_{6}=\text { Income amount }\end{array}$} & \multicolumn{3}{|c|}{$\begin{array}{l}x_{7}=\text { Similar_symptoms } \\
x_{8}=\text { Time taken to hospital } \\
x_{9}=\text { prescription_cost }\end{array}$} \\
\hline
\end{tabular}

Table 11 shows the logistic regression coefficient, Wald test, and odds ratio for each of the predictors. Employing a 0.05 criterion of statistical significance, $x_{1}, x_{3}, x_{4}, x_{5}, x_{7}$ and $x_{8}$ variables had significant effects when no doctor's Prescription. The exponentiated coefficients in the last column of the output are interpretable as multiplicative effects on doctor's Prescription. Thus, for example, holding all other variables constant, an additional unit of education level increases the likelihood of having a doctor's Prescription by afactor of 1.065 on average. We observed that the significant values of the variables $\left(x_{1}, x_{3}, x_{4}, x_{5}, x_{7}\right.$ and $\left.x_{8}\right)$ were less than 0.05 meaning they are statistically significant and the others are not, hence not included in the model below. The Wald statistic tests the unique contribution of each predictor in the context of the other predictors.

The prediction equation in this article is thus:

$$
\text { In } \frac{p}{1-p}=b_{0}+b_{1} x_{1}+b_{2} x_{2}+\cdots+b_{9} x_{9}+e
$$

where $p$ is the probability of having doctor's Prescription. Hence from the Table 11, we develop the following model.

$$
\begin{aligned}
\operatorname{In} \frac{p}{1-p}= & 2.492-0.117 x_{1}+0.194 x_{3}+0.063 x_{4} \\
& +3.154 x_{5}+0.262 x_{7}+0.088 x_{8}
\end{aligned}
$$

This result shows that there exists a relationship between the $\left(x_{1}, x_{3}, x_{4}, x_{5}, x_{7}\right.$ and $x_{8}$ ) variables. The significance of the model is less than 0.05 hence the model is statistically significant.

\subsection{Results Summary}

All the chi square tests done were able to determine that cost of prescription was significant in determining whether a patient buys drugs without a prescription. Thus the cost of accessing health care does determine the choice of OTC drugs to prescribed drugs. Source of diagnosis information, source of prescription information, amount of income of the 
respondent, previous experience on the same similar symptoms and gender were also significant in determining whether a respondent would buy drugs from a chemist without a doctors' prescription. Age, place of residence, occupation, hospital type near the respondent, nearness to a chemist / hospital, time taken to reach hospital, Awareness of dangers were all not significant in determining whether a patient will buy drugs without a medical doctors prescription. When occupations, place of residence, level of education, hospital type near respondent were entered as covariates, the overall model changed. Time taken to reach hospital, awareness of dangers and nearness to a chemist/hospital which were initially not significant became significant. These suggest that the apparent relationship between income and possessing a medical doctor's prescription is merely an artifact of the underlying relationship between education levels and having a doctor's prescription. Since income tends to rise as education rises, apparent relationships between income and other variables may actually be the result of differences in levels of education. Awareness of the dangers of buying drugs without a prescription is significant when levels of education are entered as a covariate. Since levels of awareness of dangers decreases as levels of education decreases, then processing a doctor's prescription is influenced by awareness of dangers as a result of levels of education.

More private hospitals are nearer to the respondents than government hospitals. When hospital type is entered as a covariate, then nearness to hospital which was initially not significant became significant. This shows that processing a doctor's prescription is influenced by nearness to hospital as a result of the hospital type near the respondent. Time to reach hospital was not significant in determining if a respondent had a doctors' prescription but when place of residence was entered as a covariate, then time taken to reach hospital became significant in determining if a respondent would have a doctors' prescription. This also suggests that the relationship between time taken to reach hospital and possessing a doctor's prescription is merely an artifact of the underlying relationship between nearness to hospital, place of residence to having a doctor's prescription.

\section{Conclusion and Recommendation}

\subsection{Conclusion}

This research project has contributed to the understanding of the diverse representations that are held by patients who buy drugs at community pharmacies without a doctors' prescription. It also provided some insights on how drug dispensation might be evaluated from the patient perspective. Patients who ever got sick and were treated, they tend to associate their previous similar symptoms with the current symptoms and thus they find no need of getting a medical doctors' prescription in order to buy drugs. The cost of accessing health care does determine the choice of OTC drugs. This meant that 199 out of 208 respondents preferred to buy drugs without a doctor's prescription in order to avoid extra expenses like consultation fee, laboratory fee, registration (card fee) among others. More private hospitals and clinics are located near the people than the government hospitals. These private hospitals/ clinics are expensive which makes people fear the cost of getting prescription from the doctor.

We also found that there is no relationship between awareness of the dangers of buying drugs over the counter without a medical doctor's prescription. This indicates that People are not aware of the dangers of buying drugs over the counter without a medical doctor's prescription. Possessing a doctor's prescription while purchasing OTC drugs is not determined by the time a patient takes to get services from a medical doctor in a hospital. It was found that, 77 respondents out of 114 bought OTC drugs without a prescription despite living in places where they could have taken less than 30 minutes to hospital/ clinic. Equally 74 respondents out of 108 lived in places where they could have taken less than $1 \mathrm{hr}$ yet they decided to buy OTC drugs without a medical doctor's prescription. Chemists are located nearer to the people than the hospitals and clinics across the district and thus more people live close to the chemists as compared to the hospitals. This makes the people to prefer to buy OTC drugs without necessary going to get the doctors' prescription.

Income of the respondent influences the decision of buying drugs with a medical doctors' prescription or to buy the OTC drugs without a prescription. Higher income earners tend to seek a doctors consultation as compared to low income earners who buy OTC drugs without a medical doctors' prescription. Ages of the respondents influences the decision to buy OTC drugs without a medical doctor's prescription though experience. More men than women buy OTC drugs without a medical doctors' prescription. Men don't like admitting getting sick since they take it as an element of defeat. Moreover men look down upon female doctors in hospital and more or less they don't like the questions asked in hospital and so they may opt to buy drugs without visiting a hospital for a prescription. Thus the gender of the respondents determined if one had a prescription or not when buying OTC drugs.

The source of information regarding where the respondents were suffering from determined if they had a prescription when buying the OTC drugs or not. More people preferred to get their diagnosis from the chemist than in the hospitals. Prescription is the instruction on the medicine a patient should take for a certain illness. The source of this information was highly significant in determining in the respondent had a medical doctors prescription when buying the OTC drugs.

\subsection{Recommendation}

i. The ministry of health and ministry of public health should increase the number of health facilities such as clinics and dispensaries to all areas in the district. This will reduce the time taken when accessing the medical care in the district.

ii. More awareness should be made to sensitize people on 
the dangers of buying OTC drugs without a medical doctors' prescription.

iii. The government should come up with measures to ensure that the drug sellers are qualified enough to dispense the OTC drugs.

iv. The expenses involved in getting a medical doctors prescription such as registration fee, consultation fee among others should be abolished by the government though the ministry of health and public health to make it more affordable.

\section{Acknowledgement}

Glory and honour to the Almighty God whose un ending blessings and mercies have enabled me to accomplish this research. I am grateful to my supervisor Dr. Gachangi Njenga of Kenyatta University, Mathematics Department who provided his professional support, guidance and moral enlightenment in writing this research.

\section{References}

[1] Abiola A, A. F A, Alhassan M, Famuyide A, Nwaorgu O, Olujohungbe A, Uche F, (1983). A qualitative assessment of medicine sellers in Igbo-Ora. Ibadan, Nigeria: University of Ibadan.

[2] Adome R. O, Whyte S. R, Hardon A, (1996). Popular pills: Community drug use in uganda. Amsterdam: Het Spinhuis.

[3] Anderson C, Blenkinsopp a \& Armstrong M (2004). Patients perspectives on community pharmacy sevices. Health expectations, 7: 191-202.

[4] Brieger W. R, Osamor P. E, Salami K. K, Oladepo O, Otusanya S.A, (2004). Interactions between patent medicine vendors and customers in urban and rural Nigeria. Health Policy Plan 19: 177- 182. District development plan (DDP; 2005, Thika). http://ncpd-ke.org/strategicplans/Thika.pdf

[5] Fassin D, (1988). Illicit sale of pharmaceuticals in Africa: sellers and clients in the suburbs of Dakar. Trop Geogr Med 40: $166-170$.

[6] Indalo A, (1997). Antibiotic sale behaviour in Nairobi: a contributing factor to antimicrobial drug resistance. East Afr Med J 74: 171- 173.

[7] Goel P, Ross Degnan D, Berman P, Soumerai S, (1996). Retail pharmacies in developing countries: $a$ behavior and intervention framework. Soc Sci Med 42: 1155-1161. http:/www.ajth.org/external-ref

[8] Geissler P. W, Nokes K, Prince R. J, Odhiambo R. A, AagaardHansen J, Ouma J.H. (2000). Children and medicines: selftreatment of common illnesses among Luo schoolchildren in western Kenya. Soc Sci Med 50: 1771-1783.

[9] Goodman C, Kachur S. P, Abdulla S, Mwageni E, Nyoni J, Schellenberg J. A, Mills A, Bloland P. (2004). Retail supply of malaria-related drugs in rural Tanzania: risks and opportunities. Trop Med Int Health 9: 655-663.
[10] Greenwood D. J \& Levin M. (2005). The sage handbook of qualitative research. Thousand Oaks', California.

[11] Habermas (1966). Ethical competence and moral distress in the health sector care. Sweden.

[12] KDHS (2008/2009). Preliminary results from the Kenya Demographic Health Survey.

[13] Kettis L, Kjellgren K, Ring L, Maroti M \& Serup J.(2006). The role of dermatologists, nurses and pharmacists in chronic dermatological treatment: actadermato-venereologica, 86: 202-208.

[14] Kothari C. R (2003). Research methodology. New Delhi, India. Http://www.geohive.com/cntry/kenya.aspx

[15] Marsh V. M, Mutemi W. M, Muturi J, Haaland A, Watkins W. M, Otieno G, Marsh K, (1999). Changing home treatment of childhood fevers by training shop keepers in rural Kenya. Trop Med Int Health 4: 383-389.

[16] Marsh V. M, Mutemi W. M, Willets A, Bayah K, Were S, Ross A, Marsh K, (2004). Improving malaria home treatment by training drug retailers in rural Kenya. Trop Med Int Health 9: 451- 460 .

[17] Massele A. Y, Sayi J, Nsimba S. E, Ofori Adjei D, Laing RO, (1993). Knowledge and management of malaria in Dar es Salaam, Tanzania. East Afr Med J 70: 639-642.

[18] Mcauley J. W, miller M. A, Klatte E \& Shneker B. F (2009). Patients with epilepsy's perception on community pharmacist's current and potential role in their care. Epilepsy and behavior, 14: $141-145$.

[19] Nshakira N, Kristensen M, Ssali F, Whyte S.R. (2002). Appropriate treatment of malaria? Use of antimalarial drugs for children's fevers in district medical units, drug shops and homes in eastern Uganda. Trop Med Int Health 7: 309-316.

[20] Ongore D \& Nyabola L. (1996). Role of shops and shopkeepers in malaria control. East Afr Med J 73: 390-394.

[21] Salter C, Holland R, Harvey I, Henwood K. (2007). Assessing pharmacists' impacts in primary health care: Trent University, Peterborough, Ontario, Canada.

[22] Schommer J. C (1997). Patients perspectives on community pharmacy services American Journal of Pharmaceutical Education, 61: 402-406

[23] Strauss \& Corbin. (1998) Basics of Qualitative Techniques, uk

[24] Tawfik Y, Nsungwa-Sabitii J, Greer G, Owor J, Kesande R, Prysor-Jones S. (2006). Negotiating improved case management of childhood illness with formal and informal private practitioners in Uganda. Trop Med Int Health 11: 967-973.

[25] Wolf-Gould C, Taylor N, Horwitz S, Barry M. (1991). Misinformation about medications in rural Ghana. Soc Sci Med 33: 83- 89.

[26] Van der Geest S, (1998). The articulation of formal and informal medicine distribution in south Cameroon. The Netherlands: Kluwer Academic Publishers.

[27] Van der Geest S, 1987. Self-care and the informal sale of drugs in south Cameroon. Soc Sci Med 25: 293-305. 